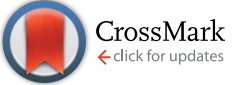

Cite this: RSC Adv., 2017, 7, 14168

\title{
Intercalation behaviour of magnesium into natural graphite using organic electrolyte systems $\uparrow$
}

\author{
C. God, ${ }^{a}$ B. Bitschnau, ${ }^{\text {b K. Kapper, }}{ }^{\text {a }}$ C. Lenardt, ${ }^{a}$ M. Schmuck, ${ }^{\star a}{ }^{\text {F }}$. Mautner ${ }^{\text {b }}$ \\ and S. Koller ${ }^{\mathrm{a}}$
}

The focus of this study is on the investigation of electrochemical intercalation and deintercalation behaviour of $\mathrm{Mg}^{2+}$ into natural graphite electrodes in organic electrolyte. We used as a conductive salt magnesium bis(trifluoromethylsulfonyl)imide $\left(\mathrm{Mg}(\mathrm{TFSI})_{2}\right)$ dissolved in $\mathrm{N}, \mathrm{N}$-dimethylformamide (DMF) as organic solvent. By utilization of conductivity measurements within a broad temperature range $\left(-20{ }^{\circ} \mathrm{C}\right.$ to +60 ${ }^{\circ} \mathrm{C}$ ), a conductivity maximum is to be found at a concentration of $0.5 \mathrm{M}$ for all temperatures. Thus, in this study all electrochemical investigations dealing with magnesiation of graphite anodes are made with the electrolyte system 0.5 M Mg(TFSI) 2 /DMF. In three electrode cells (Swagelok@ T-cells) we obtain cathodic and anodic currents, which are highly reversible and last for more than 100 cycles showing a coulombic efficiency above $98 \%$. SEM images reveal a non-destructive intercalation of cationic species into graphite and the formation of a magnesiated graphite intercalation compound is confirmed by ex situ XRD diffraction measurements.

Received 16th December 2016 Accepted 20th February 2017

DOI: $10.1039 / c 6 r a 28300 d$

rsc.li/rsc-advances

consequence. However, research of LIBs has to tackle both going to their energy limit and more importantly, challenges such as their needed recharge time, enormous costs and inherent safety issues. ${ }^{4}$ LIB systems using Li-metal as an anode in order to provide a sufficient energy density, e.g. lithiumsulfur or lithium-air batteries, suffer from intrinsic properties of lithium itself. Unfortunately, lithium deposits on the anode's surface in the shape of needles, well known as dendrites. With subsequent battery cycling and continuous growth of the needle-like crystals severe safety issues may occur because they are able to provoke an internal short circuit by growing from anode to cathode resulting in dangerous fire hazards. ${ }^{5,6}$ Since then lithium metal as the ultimate metal anode is replaced by carbonaceous materials, which act as host materials for reversible lithium-ion intercalation and deintercalation. However, Li-insertion and distraction mechanism occur at potentials close to that of lithium metal, connoting, too, grave safety issues by lithium plating, e.g. in case of an inadequate cell balancing. On this account alternative technologies beyond lithium-ion batteries are needed if the desire of safe, cheap, well performing and in particular high energy batteries providing even a long cycle life shall be retained. Considering properties such as a rather low reduction potential $(-2.36 \mathrm{~V} v s$. SHE), high

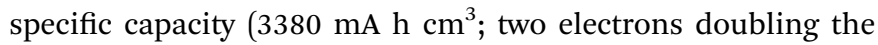
charge carried per volume), low equivalent weight and moreover, sufficient safety due to a non-dendritic metal deposition, magnesium-ion batteries appear to be competitive to lithiumion batteries. ${ }^{2}$

Since organic, aprotic electrolyte systems create a passivation layer on the $\mathrm{Mg}$-metal surface preventing a reversible $\mathrm{Mg}$ - 
deposition and dissolution, corrosive electrolytes such as Grignard reagents $(\mathrm{RMgX}, \mathrm{R}=$ alkyl; $\mathrm{X}=\mathrm{Br}, \mathrm{Cl})$ have to be used. ${ }^{7,8}$ Indeed, organometallic Grignard reagents can be reversibly reduced and oxidized but exhibit only a small stability window, that is, decomposition takes place above $1.5 \mathrm{~V} v s . \mathrm{Mg} /$ $\mathrm{Mg}^{2+}$. Moreover, their feasible application in secondary batteries is limited due to their chemical incompatibility with battery components, e.g. insertion cathode materials. Accordingly, research focuses mainly on further development of these electrolytes with a sufficient oxidative behaviour in order to realize the ambitious goal of a secondary $3 \mathrm{~V} \mathrm{Mg}$-battery system which is needed to be competitive to LIB. Such required electrolytes are based on ethereal solutions consisting of magnesium organohaloaluminate salts which were part of Aurbach's pioneering magnesium work already done in the year 2000..$^{5,9}$ Unfortunately, all these Grignard and Grignard-like electrolytes prone to corrode metals like aluminium, copper, nickel, titanium, etc. The implementation of which is conceivable as current collectors for the positive electrode. ${ }^{10,11}$ A strategy to circumvent this issue and to achieve the ambitious $3 \mathrm{~V}$ goal is the development of intercalation/insertion anode compounds like $\mathrm{Ge}, \mathrm{Si}, \mathrm{Sn}$ or graphite and the replacement of corrosive electrolytes by organic solvents and $\mathrm{Mg}$-conductive salts in combination with common metal oxide cathode materials. ${ }^{\mathbf{1 2 - 1 4}}$ Besides a sufficient oxidative stability organic electrolytes provide ( $>3.5 \mathrm{~V}$ vs. $\mathrm{Mg} / \mathrm{Mg}^{2+}$ ) even the chemical compatibility with the above mentioned current collector materials can be achieved at the same time which would enable the $3 \mathrm{~V}$ magnesium-ion battery (MIB) in the end. ${ }^{15-17}$

Graphite intercalation compounds (GIC) are still the reason behind the success of lithium-ion batteries until today, so lots of effort is still devoted to lithium intercalation into graphite with regard to improve cycle life of LIB, while only little to no information is available for the intercalation behaviour of magnesium into graphite. According to literature it is assumed that $\mathrm{Mg}$-intercalation into graphite is impossible due to strong interfacial reduction reactions especially during the first cycle. Accordingly, organic electrolytes prone to get decomposed, form a passivation layer on the graphite surface and show even solvated intercalation and solvent cointercalation respectively leading to irreversible exfoliation of graphite itself. ${ }^{\mathbf{1 8 , 1 9}}$ Pontiroli et al., on the contrary, identified the phase $\mathrm{Mg}_{2} \mathrm{C}_{60}$ by intercalation of magnesium into fullerenes and could prove the same bonding architecture as the intercalated fulleride $\mathrm{Li}_{4} \mathrm{C}_{60}$ exhibits. ${ }^{20}$ This raises the question of whether the same phase of intercalated graphite compounds can be observed as well. From electrochemical point of view, the theoretical phase of magnesiated graphite would be hypothetically $\mathrm{Mg}_{0.5} \mathrm{C}_{6}$ with reference to the full lithiated graphite phase $\mathrm{LiC}_{6}$ both exhibiting the same theo-

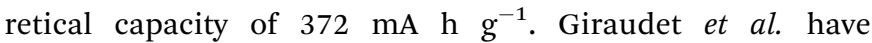
successfully inserted $\mathrm{Mg}^{2+}$ ions into graphite fluorides by using conventional aprotic electrolytes. ${ }^{21}$ However it should be mentioned that a structural unstableness for $(\sqrt{3} \times \sqrt{3}) R 30^{\circ}$ $\mathrm{MgC}_{6}$ monolayer is predicted by means of density-functional theory (DFT) and ab initio molecular dynamic simulations. ${ }^{22}$
As a consequence, in this study we want to shed light on the intercalation behaviour of magnesium into graphite showing an apparently non-destructive, reversible magnesiation and demagnesiation (intercalation and deintercalation) of common natural graphite composite electrodes in combination with common organic, aprotic electrolytes.

\section{Experimental}

Graphite based anodes were prepared by dissolution of $7 \mathrm{w} \%$ polyvinylidene fluoride (PVDF, Solef® 5130 , Solvay) in $N$-methyl2-pyrrolidone (NMP, $\geq 99.8 \%$, Sigma-Aldrich) with subsequent addition of $90 \mathrm{w} \%$ natural graphite (Qingdao Nanshu Graphite Co., Ltd., average size $20 \mu \mathrm{m}$ ) and $3 \mathrm{w} \%$ carbon black (Super-P, Timcal Ltd.). The resulting slurry was stirred over night to provide a uniform mixture. The slurry is applied onto a copper foil by using the doctor blade technique (Erichsen Multicator 411 with a gap of $150 \mu \mathrm{m}$ and Erichsen 509 coater). The subsequent steps were removal of NMP in an oven at $70{ }^{\circ} \mathrm{C}$, punching of $12 \mathrm{~mm}$ electrode discs and again drying of the obtained electrodes in a glasstube furnish (Büchi) for about 24 hours at $100{ }^{\circ} \mathrm{C}$ under vacuum $\left(<10^{-1} \mathrm{mbar}\right)$. The electrodes were weighed for determination of their actual active masses per electrode and were dried once again under the same conditions as described before. The final mass loadings of the electrodes were 1.8 to $2.1 \mathrm{mg} \mathrm{cm}^{-2}$.

Both electrolyte and electrochemical cell preparations were carried out in an Ar-filled glove box $\left(\mathrm{O}_{2}\right.$ and $\left.\mathrm{H}_{2} \mathrm{O}<1 \mathrm{ppm}\right)$. For the electrolyte preparation magnesium-bis-(trifluoromethylsulfonyl)imide $\left(\mathrm{Mg}(\mathrm{TFSI})_{2}, 99.5 \%\right.$, Solvionic) as conductive salt was added to $\mathrm{N}, \mathrm{N}$-dimethylformamide (DMF, anhydrous, 99.8\%, Sigma Aldrich) in desired concentrations in a range from 0.1 to $1.2 \mathrm{~mol} \mathrm{l}^{-1}$ in order to determine a possible conductivity maximum in dependence of the concentration. $\mathrm{Mg}(\mathrm{TFSI})_{2}$ was vacuum dried before use and DMF was dehydrated over molecular sieve ( $4 \AA$ ) for several days. The water content was determined by Karl-Fischer titration technique showing values below 20 ppm. Conductivity measurements of all electrolyte concentrations were performed with a Knick-703 conductometer in a temperature range from $-20{ }^{\circ} \mathrm{C}$ to $+60{ }^{\circ} \mathrm{C}$ operating with a fourelectrode sensor. Calibration of the cell constant was made with standard solutions before all conductivity measurements $(0.1 \mathrm{M}$ $\mathrm{NaCl})$. The dynamic viscosity of all electrolytes was determined within the same temperature range just as the conductivity measurements were done. For the viscosity determination a Stabinger viscometer SVM 3000 from Anton Paar was used.

All electrochemical tests were conducted in a three electrode arrangement in Swagelok-cells with graphite anodes as working electrodes and magnesium metal as counter and reference electrodes (Goodfellow, 99.9\%). Prior to cell assembly, both counterand reference electrodes were polished beforehand in order to remove the oxidized magnesium layer. A polypropylene nonwoven separator (Freudenberg FS 2190) was wetted with 150 $\mu \mathrm{l}$ of non-aqueous electrolyte $0.5 \mathrm{M} \mathrm{Mg}(\mathrm{TFSI})_{2}$ in DMF. Cyclic voltammetry (CV) and constant current cycling (CCC) measurements were recorded on a Bio-Logic MPG-2 battery test station with a scan rate of $0.05 \mathrm{mV} \mathrm{s}^{-1}$ for the $\mathrm{CV}$ and different C-rates 
(0.005C to $0.1 \mathrm{C})$ for up to 100 complete charge/discharge CCC cycles.

The morphology of graphite electrodes before and after electrochemical tests was analysed by Tescan Vega3 scanning electron microscope (SEM) equipped with an Oxford Instruments INCAx-act energy dispersive X-ray (EDX). Cycled electrodes were washed in dry acetone to remove electrolyte residues prior to SEM investigations.

Ex situ X-ray diffraction (XRD) patterns of magnesiated and demagnesiated graphite anodes were recorded on a Bruker D8 powder diffractometer $(\mathrm{Cu}-\mathrm{K} \alpha$ radiation, diffraction range of 10 to $80^{\circ} 2 \theta$, step with $0.02^{\circ} 2 \theta$, scan rate: 0.1 to $0.2 \mathrm{~s}$ per step). In order to exclude any contact of the magnesiated and demagnesiated graphite electrodes with atmospheric oxygen and moisture the anodes were investigated in in-house built ex situ cells equipped with a beryllium window which were assembled in an Ar-filled glove-box. X'Pert High Score Plus (PANalytical) was used for analysis.

\section{Results and discussion}

\section{Conductivity and viscosity measurement}

Conductivity measurements are made to determine the optimum conductivity of a non-aqueous electrolyte based on $\mathrm{Mg}(\mathrm{TFSI})_{2}$ and DMF in dependence on the conductive salt concentration. The reason for the choice of the electrolyte salt $\mathrm{Mg}(\mathrm{TFSI})_{2}$ is its adequate commercial availability with a reasonable purity and more importantly, it is easy to dissolve in organic, aprotic solvents many magnesium salts do not provide. For instance, magnesium trifluoromethane sulfonate $\left(\mathrm{Mg}(\mathrm{Tf})_{2}\right)$ exhibits insufficient solubility merely. Even if $\mathrm{Mg}(\mathrm{TFSI})_{2}$ is fairly soluble in several organic solvents DMF is chosen for this study due to its high donor number (Gutmann's $\mathrm{DN}=26.5$ ), strong dipole moment and low acceptor number, thus, providing high solubility/solvation abilities and weak interactions with anions. ${ }^{23,24}$ No solubility problems should arise even at higher salt concentrations in this way. Fig. S1 (ESI $\dagger$ ) displays the recorded conductivity of different salt concentrations starting with a $0.1 \mathrm{M}$ concentration stepwise up to $1.2 \mathrm{M} \mathrm{Mg}(\mathrm{TFSI})_{2}$ (0.2 steps) and reveals the existence of a conductivity maximum at a $0.5 \mathrm{M}$ salt concentration in DMF for all temperatures $\left(-20{ }^{\circ} \mathrm{C}\right.$ to $\left.+60{ }^{\circ} \mathrm{C}\right)$. At $+30{ }^{\circ} \mathrm{C}$ the conductivity is $16.87 \mathrm{mS} \mathrm{cm}{ }^{-1}$ which is almost three times the conductivity value of $\mathrm{MgCl}_{2}: \mathrm{Mg}(\mathrm{TFSI})_{2}$ (2.5:1 in 1,2 dimethoxyethane) showing the best conductivity among mixtures of magnesium salts $\left(5.80 \mathrm{mS} \mathrm{cm}{ }^{-1}\right.$ at $\left.+28{ }^{\circ} \mathrm{C}\right) .{ }^{25}$ Determination of the dynamic viscosity ( $c f$. Fig. S2, ESI $\dagger$ ) reveals a non-linear behaviour and more importantly, the freezing of the electrolyte when salt concentrations exceed 0.5 M. With regard to the conductivity maximum and the freezing behaviour it seems reasonable to favour a concentration of $0.5 \mathrm{M} \mathrm{Mg}(\mathrm{TFSI})_{2}$ in DMF for all further electrochemical investigations.

\section{Electrochemical experiments}

Electrochemical tests are conducted in Swagelok@-half cell configuration to determine the electrochemical behaviour of a natural graphite anode in the DMF based electrolyte containing $0.5 \mathrm{M} \mathrm{Mg}(\mathrm{TFSI})_{2}$. The voltage ranges for individual cyclic voltammetry scans are set to values between -0.5 to $+1.0 \mathrm{~V} v s$. $\mathrm{Mg} / \mathrm{Mg}^{2+}$ at a scan rate of $0.05 \mathrm{mV} \mathrm{s}^{-1}$. As a result, (cf. Fig. 1) three broad reduction peaks appear below a potential threshold of $+0.15 \mathrm{~V}$ vs. $\mathrm{Mg} / \mathrm{Mg}^{2+}$. In the subsequent anodic sweep three oxidation peaks can be observed between -0.20 and $+0.4 \mathrm{~V} v s$. $\mathrm{Mg} / \mathrm{Mg}^{2+}$ connoting that all cathodic peaks are reversible. In an analogous manner further eligible electrolytes were characterized with solvents which exhibit a sufficient solubility for $\mathrm{Mg}(\mathrm{TFSI})_{2}$. An intercalation phenomenon comparable to DMF based electrolytes could be observed with dimethylacetamide (DMA) as a solvent ( $c f$. Fig. S4 (ESI $\dagger)$ ).

Since the inorganic electrolyte salt is dissolved in DMF the only cation species in the electrolyte are magnesium-ions. That implies that both cathodic and anodic reactions suggests a kind of intercalation and deintercalation of $\mathrm{Mg}^{2+}$ between and from the graphene layers respectively. However, the electrochemical reactions exhibit merely a practical capacity during the first cycle of $c a .40 \mathrm{~mA} \mathrm{~h}^{-1}$ and the coulombic efficiency reveals an irreversible capacity loss of about $30 \%$. The capacity loss decreases with subsequent cycling indeed, but even in the second and third cycle irreversible capacity can be still detected and reaches values up to $10 \%$. This quite high capacity loss and irreversible capacity, respectively, can be attributed to either continuous electrolyte reduction and/or remaining magnesiumions within the graphite interlayer.

Since the practical capacity only reaches values of around 35$40 \mathrm{~mA} \mathrm{~h} \mathrm{~g}{ }^{-1}$ in the first cycles the negative cut-off voltage is adjusted to $-0.25 \mathrm{~V}$ vs. $\mathrm{Mg} / \mathrm{Mg}^{2+}$ trying to enhance practical capacity ( $c f$. Fig. S3 (ESI $\dagger$ )). Once the graphite anode is polarized to this negative potential the third cathodic peak at $-0.2 \mathrm{~V}$ is much more distinct compared to the previous cycle and the capacity increases to $53 \mathrm{~mA} \mathrm{~h} \mathrm{~g}^{-1}$ and $40 \mathrm{~mA} \mathrm{~h} \mathrm{~g}^{-1}$ respectively (charge- and discharge capacity). By adjusting the lower vertex potential to even more negative values below $-0.25 \mathrm{~V} v s . \mathrm{Mg} /$

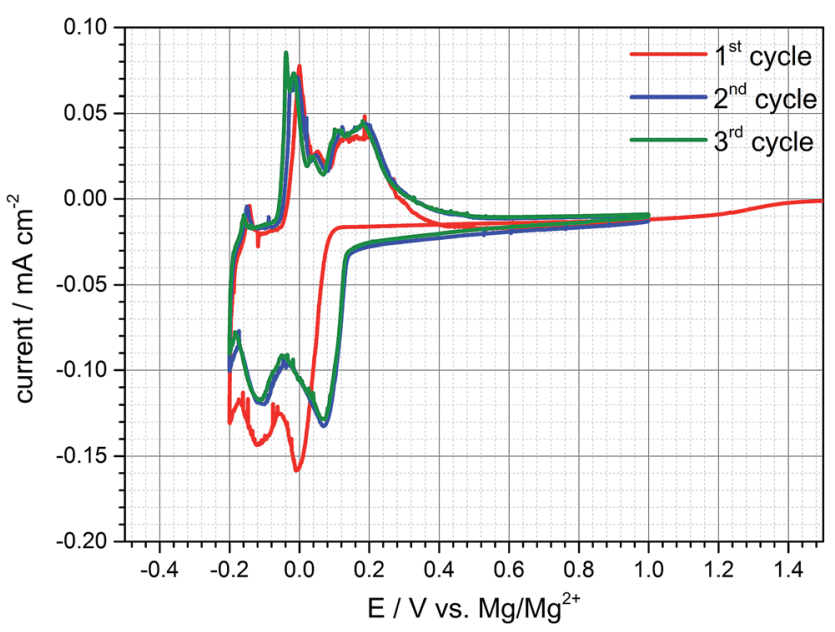

Fig. 1 Typical cyclic voltammogram of a natural graphite anode in $0.5 \mathrm{M} \mathrm{Mg}(\mathrm{TFSI})_{2}$ in DMF at a scan rate of $0.05 \mathrm{mV} \mathrm{s}^{-1}$ showing reversible cathodic and anodic peaks suggesting intercalation and deintercalation of magnesium ( -0.2 to $1.0 \mathrm{~V} \mathrm{vs}$. $\mathrm{Mg} / \mathrm{Mg}^{2+}$ ). 
$\mathrm{Mg}^{2+}$ large reduction currents can be observed with little to no oxidation currents in the subsequent anodic sweep during the cyclic voltammogram. As is obvious from Fig. 2, after polarizing the anode to more than even $-0.4 \mathrm{~V}$ and $-0.5 \mathrm{~V}$ vs. $\mathrm{Mg} / \mathrm{Mg}^{2+}$ large reduction currents appear and the corresponding oxidation peaks shift from around $0 \mathrm{~V}$ to $+0.7 \mathrm{~V}$. This behaviour can be related to magnesium deposition and electrolyte decomposition, respectively, below $-0.3 \mathrm{~V}$ and magnesium dissolution at around $+0.6 \mathrm{~V} v s$. $\mathrm{Mg} / \mathrm{Mg}^{2+}$. The shifted oxidation peak indicates a huge overpotential for the dissolution process which is hardly reversible emphasizing electrolyte decomposition and mainly forming a passivation layer on the graphite anode's surface. The deintercalation process within the range of $-0.2 \mathrm{~V}$ to $1.0 \mathrm{~V} v s$. $\mathrm{Mg} / \mathrm{Mg}^{2+}$ cannot be observed anymore for being inhibited by the passivation layer. Deeper polarization might lead to competitive reactions between magnesium intercalation, electrolyte reduction and magnesium metal deposition. This gives cause for remaining above this vertex potential to prevent these undesired reactions of electrolyte decomposition and passivation of the negative electrode's surface.

Fig. 3a and b display the morphology of natural graphite anodes before and after electrochemical experiments with $0.5 \mathrm{M}$ $\mathrm{Mg}(\mathrm{TFSI})_{2}$ in DMF respectively. In the SEM images no exfoliation behaviour is detectable as long as the anode is not polarized to more negative potentials than $-0.20 \mathrm{~V} v s . \mathrm{Mg} / \mathrm{Mg}^{2+}$. In comparison to the pristine graphite anode flat flakes of graphite particles with distinct edges are observable after cycling but the entire surface morphology of the graphite electrode is still homogeneous. Since the particles themselves do not become bigger after cycling almost no volume change of the particles is assumed which would be caused by expansion of solvated intercalation/deintercalation processes. The cycled electrode additionally shows particles dispersed on graphite's surface reflecting electrolyte reduction reaction which is common for conventional electrolyte reduction processes. ${ }^{26}$ Nevertheless,

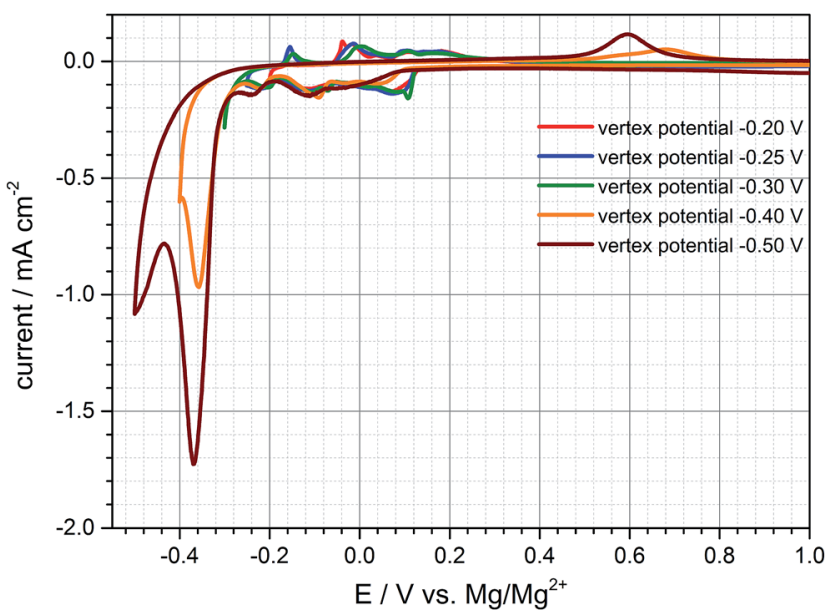

Fig. 2 Negative vertex potentials below $-0.25 \mathrm{~V} v \mathrm{vs} . \mathrm{Mg} / \mathrm{Mg}^{2+}$ worsen reversible electrochemical reactions of magnesium intercalation/ deintercalation into/from graphite and lead to $\mathrm{Mg}$-metal deposition and severe electrolyte decomposition in combination with shifted anodic peaks and huge overpotentials respectively.
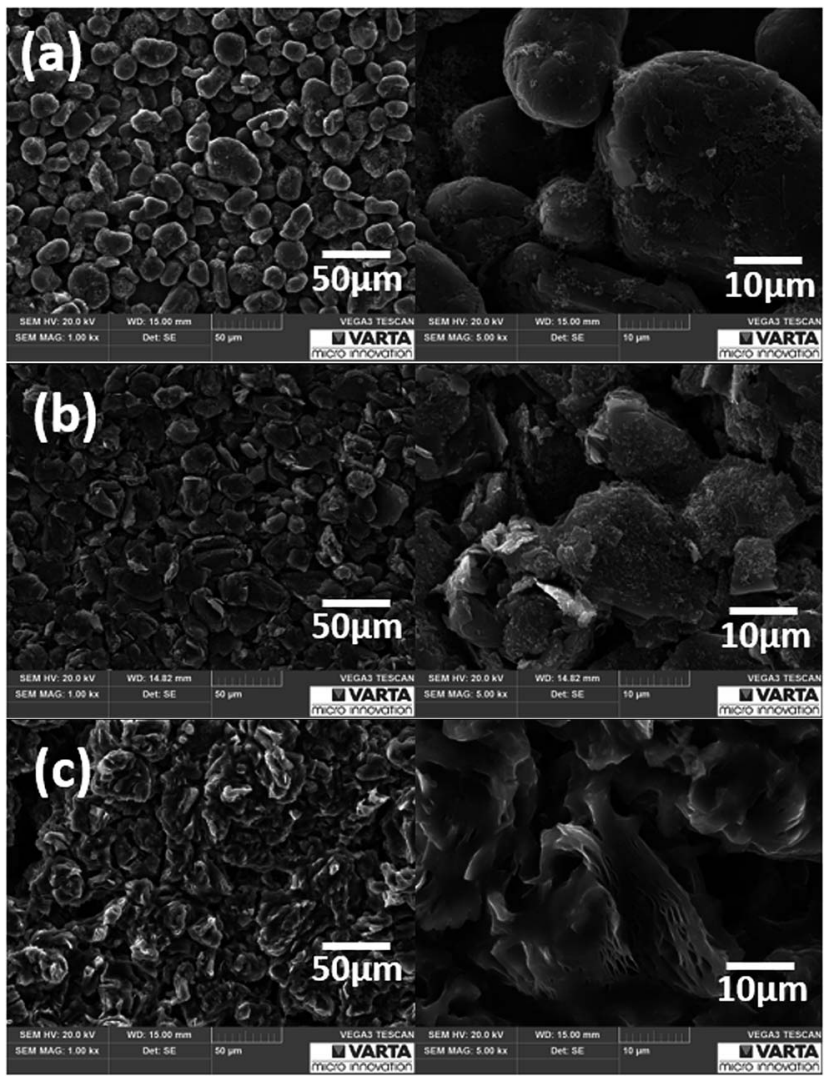

Fig. 3 (a) SEM images of a pristine graphite anode showing the potatoe shaped graphite particles. (b) SEM images of a cycled graphite anode in $0.5 \mathrm{M} \mathrm{Mg}(\mathrm{TFSI})_{2} / \mathrm{DMF}$ revealing a homogeneous electrode surface after many electrochemical cycles. (c) SEM images of the graphite surface after polarizing the electrode below $-0.3 \vee$ vs. $\mathrm{Mg} /$ $\mathrm{Mg}^{2+}$ and to deeper voltages leading to passivation and exfoliation of the graphite particles.

the cycled electrode resembles pristine graphite electrodes and the electrolyte seems to prone to reduction and formation of a "SEI-like interphase layer".

According to Fig. 3c magnesium metal deposition and massive electrolyte reduction take place forming a passivation layer on the anode's surface which is consistent with the electrochemical results obtained in the cyclic voltammetry in Fig. 2 . Graphite particles change their shape because once the graphite anode is polarized below $-0.30 \mathrm{~V}$ vs. $\mathrm{Mg} / \mathrm{Mg}^{2+}$ exfoliation of graphite occurs as well. Obviously, metal deposition and exfoliation seem to be preferred to reversible intercalation/ deintercalation reactions at greater polarization then.

The charge and discharge profiles of the galvanostatic cycles recorded at $0.1 \mathrm{C}$ exhibit a similar electrochemical behaviour as obtained in the cyclic voltammetry ( $c f$. Fig. $4 \mathrm{a}$ ). In the first cycle a practical capacity of $35 \mathrm{~mA} \mathrm{~h} \mathrm{~g}^{-1}$ and a rather high irreversible capacity of $25 \%$ can be observed while the coulombic efficiency increases with ongoing cycling and reaches values higher than $98 \%$ after the $7^{\text {th }}$ cycle. Apparently, the galvanostatic cycling shows a high reversibility of the intercalation and deintercalation of magnesium-ions into and from graphite for more than 100 cycles in the Swagelok@ half-cell. Moreover, the charge 

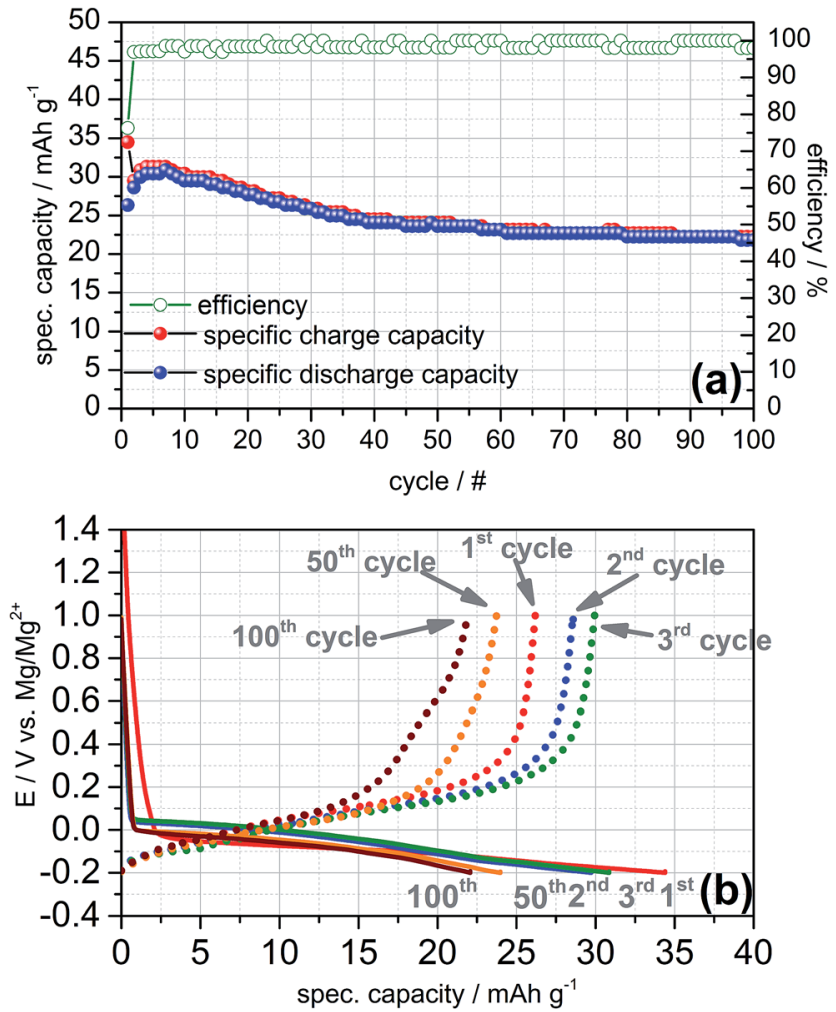

Fig. 4 (a) Constant current cycling at a rate of $0.1 \mathrm{C}$ in a cut-off potential range $-0.2 /+1.0 \mathrm{~V}$ vs. $\mathrm{Mg} / \mathrm{Mg}^{2+}$ showing a highly reversible cycling of magnesium intercalation/deintercalation on a natural graphite anode in $0.5 \mathrm{M} \mathrm{Mg}(\mathrm{TFSI})_{2} / \mathrm{DMF}$. (b) Plateaus of selected charge (solid lines) and discharge curves (dotted lines) of the constant current cycling experiment clarify the intercalation/deintercalation of magnesium into and from the graphite anode instead of sheer electrolyte decomposition.

and discharge plateaus are consistent with the cathodic and anodic peaks shown in the cyclic voltammograms ( $c f$. Fig. 4b). The plateaus of the charging steps are close to $+0.15 \mathrm{~V} v s . \mathrm{Mg} /$ $\mathrm{Mg}^{2+}$ and thus, could be ascribed to magnesium intercalation of $\mathrm{Mg}^{2+}$-ions in between the graphene layers as well. With increasing number of electrochemical cycles the intercalation plateau is continuously shortening and exhibits a practical capacity of $22 \mathrm{~mA} \mathrm{~h} \mathrm{~g}^{-1}$ for the $100^{\text {th }}$ cycle finally.

According to literature a reversible, non-destructive intercalation of $\mathrm{NR}^{+}$-cations without solvent co-intercalation into graphite occurs when, e.g. tetrabutylammonium tetrafluoroborate (TBA-BF 4 ) is dissolved in organic solvents. ${ }^{27-30}$ In order to compare the intercalation behaviour between $\mathrm{Mg}^{2+}$ and $\mathrm{TBA}^{+}$-cations and to deepen the knowledge which intercalation reactions take place we recorded a cyclic voltammogram of a graphite anode $v s$. $\mathrm{Mg}$ metal as counter- and reference electrode using $0.1 \mathrm{M}$ TBA-BF 4 in DMF.

Fig. 5 shows the cyclic voltammetry behaviour and reveals distinct intercalation and deintercalation peaks, which can be attributed to insertion/deinsertion of $\mathrm{TBA}^{+}$-cations in the first cycle. The cathodic and anodic reactions in the second cycle resemble the magnesiation/demagnesiation behaviour of graphite. However, this measurement setup comprises $\mathrm{Mg}$

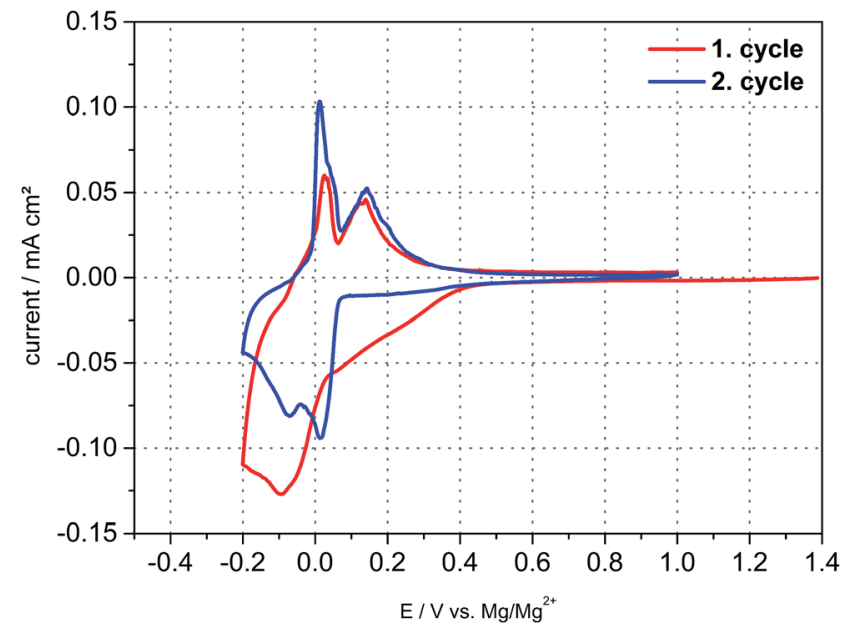

Fig. 5 Cyclic voltammogram of a natural graphite electrode vs. magnesium metal in $0.1 \mathrm{M} \mathrm{TBA}-\mathrm{BF}_{4} / \mathrm{DMF}$ at a scan rate of $0.05 \mathrm{mV} \mathrm{s}^{-1}$. The intercalation and deintercalation of $\mathrm{TBA}^{+}$-ions into and from graphite resembles the intercalation behaviour of magnesium into graphite.

metal as counter electrode, that is, maybe the CV-behaviour originates from $\mathrm{Mg}^{2+}$-cations as well due to oxidation of the counter electrode pretending the intercalation of $\mathrm{TBA}^{+}$-ions. The question arises anyhow what species intercalates into graphite reversibly since no other cation apart from $\mathrm{Mg}^{2+}$ exists in $0.5 \mathrm{M} \mathrm{Mg}(\mathrm{TFSI})_{2} / \mathrm{DMF}$ electrolyte and in case of the TBA based one both cations may coexist showing an almost exact intercalation behaviour. Nevertheless, the possibility of a solvated co-intercalation still might be applicable.

\section{X-ray diffraction measurements}

For determination whether solvated intercalation and/or merely magnesiation of graphite takes place ex situ X-ray diffraction is employed.

Fig. 6 displays the X-ray diffraction patterns of the intercalated natural graphite electrode prepared by two full cycles of cyclic voltammetry and a subsequent charging step in the $0.5 \mathrm{M}$ $\mathrm{Mg}(\mathrm{TFSI})_{2}$ in DMF electrolyte (half-cycle/charge to $-0.2 \mathrm{~V} v$ s. $\mathrm{Mg} / \mathrm{Mg}^{2+}$ at $\left.0.05 \mathrm{mV} \mathrm{s}^{-1}\right)$. The graphite diffraction peak is clearly observed at a $2 \theta$ angle of $26.70^{\circ}$. After the charging step to $-0.2 \mathrm{~V} v$ s. $\mathrm{Mg} / \mathrm{Mg}^{2+}$ this peak is shifted to $2 \theta$ angle $26.03^{\circ}$ suggesting the widening of the graphene layers and the formation of a graphite interlayer compound of $\mathrm{Mg}$ as a consequence. A completely new diffraction peak appears at an angle of $30.05^{\circ} 2 \theta$ as well and is an indication of staging, that suggesting $\mathrm{Mg}$ cations in only every $n$th space between graphene sheets. ${ }^{31}$ Moreover, this additional peak will disappear during the charging step in case of a solvated intercalation because organic solvent molecules will be decomposed at a certain potential. By contrast, however, its presence can be attributed to the intercalation of magnesium-ions merely. Thus, the intercalated magnesium-ions are not reduced within graphene layer during the charging step. Wagner et al. investigated the XRD behaviour of PC-solvated $\mathrm{Li}^{+}$-ions into graphite leading to the formation of 


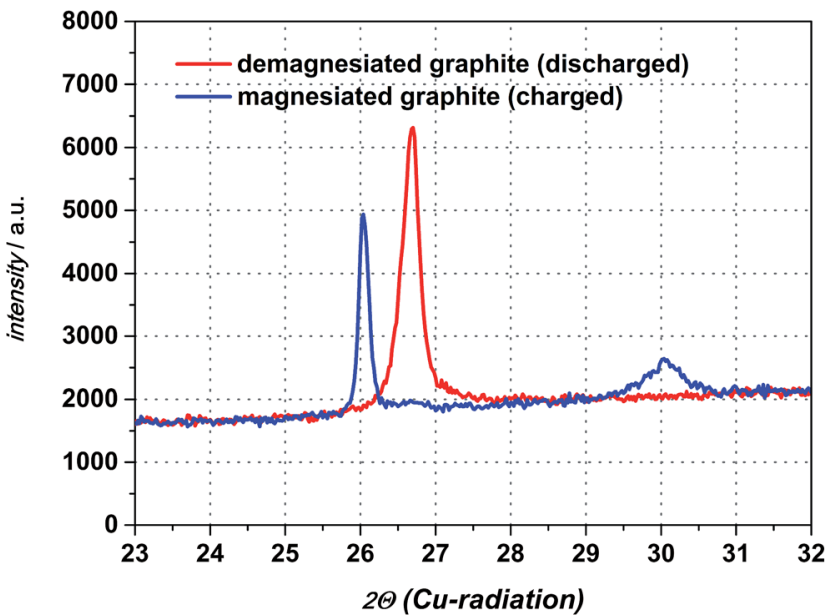

Fig. 6 XRD diffraction patterns of magnesiated graphite electrode and the original graphite diffraction peak obtained after discharging the electrode.

ternary solvated compounds with the formula $\mathrm{Li}_{x}(\mathrm{PC})_{y} \mathrm{C}_{n}{ }^{32}$ In their study an additional diffraction peak at $27.5^{\circ} 2 \theta$ appears as well and the intensity of the original graphite diffraction peak distinctly decreases at the same time. These observed changes are definitely ascribed to co-intercalation of PC and solvated $\mathrm{Li}^{+}$ions respectively. In case of magnesiated graphite the additional peak at $30.05^{\circ} 2 \theta$ appears indeed, but the intensity of the graphite peak remains more or less the same and shifts to a lower angle only favouring the intercalation of magnesiumions only. After discharging the graphite electrode the additional peak at $30.05^{\circ} 2 \theta$ disappears completely and the peak at $26.03^{\circ} 2 \theta$ shifts back again to the pristine graphite diffraction peak at $26.70^{\circ} 2 \theta$ with a similar intensity suggesting a nondestructive and highly reversible magnesiation/ demagnesiation without irreversible structure damages of the graphite respectively ( $c f$. Fig. 7).

The calculation of the obtained diffraction peaks give the characteristic $d$-value for the pristine graphite lattice constant $(d$

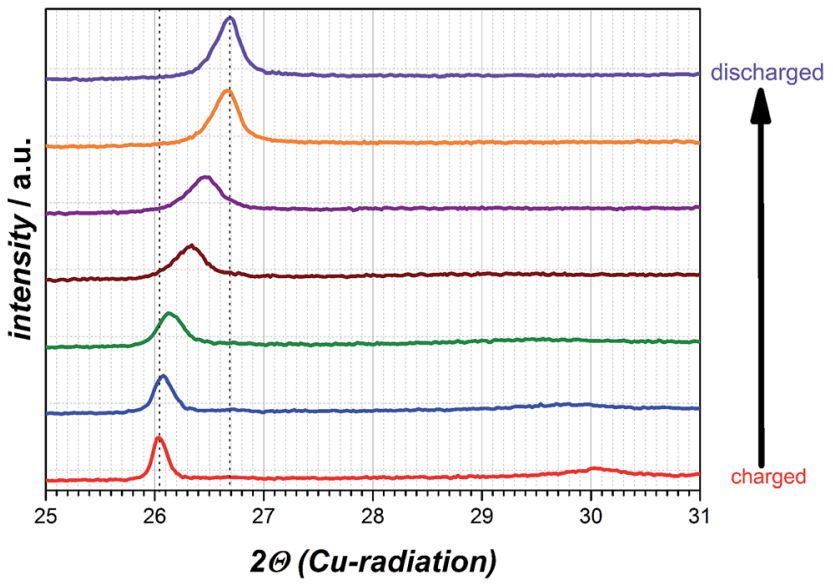

Fig. 7 Diffraction patterns obtained at different degrees of discharging the electrode.
$=3.356 \AA$ A). More importantly, the XRD measurement confirms the formation of an intercalated crystalline phase by showing an additional $d$-value for the charged graphite anode. In order to estimate the degree of intercalation by magnesiation of graphite it might be helpful to compare these $d$-values with those of lithiated graphite compounds due to very similar ionic radii of both metals $\left(60 \mathrm{pm}\right.$ for $\mathrm{Li}^{+}$and $65 \mathrm{pm}$ for $\left.\mathrm{Mg}^{2+}\right) \cdot{ }^{24}$ Table 1 summarizes the comparison of $d_{\mathrm{n}}$-values for lithiated graphite taken from literature and the experimentally determined $d_{\mathrm{n}^{-}}$ value for magnesiated graphite. ${ }^{33-35}$ As clearly seen in this table, the repeated graphite interlayer distance of the magnesiated species is quite close to the lithiated one at an intercalation stage corresponding to $\mathrm{Li}_{x} \mathrm{C}_{6}(x=0.17)$. The most remarkable fact is, though, that the interlayer distance only widened up a little bit for both intercalated compounds. In case of solvated intercalation it can be concluded that the size of solvated alkali earth metal plays an important role. Magnesium is six-solvated in the organic solvent DMF giving $\left[\mathrm{Mg}(\mathrm{DMF})_{6}\right]^{2+}$ and the bond length of magnesium to one of the oxygen atoms of DMF $r_{\mathrm{M}-\mathrm{O}}$ is $210 \mathrm{pm}^{.36,37}$ By taking into account that magnesium is sixcoordinated, the estimated order for the size of solvated $\mathrm{Mg}^{2+}$ ions will exceed for sure by a factor the bond length of $r_{\mathrm{M}-\mathrm{O}}$. The $\mathrm{Mg}-\mathrm{O}$ distance in DMF with $210 \mathrm{pm}$ indicates that the length of only one solvent molecule to $\mathrm{Mg}$ is much bigger than the obtained $d$-value of the magnesiated graphite compound reflects. Assuming a similar magnesiation GIC with regard to full lithiation of graphite the distance between the graphene layers would be still smaller than one solvated magnesium ion with the formula $\left[\mathrm{Mg}(\mathrm{DMF})_{6}\right]^{2+}$. Besenhard et al., for instance, showed for a stage-1-GIC formation a $d$-value of $1.25 \mathrm{~nm}$ resulting from the reduction of $\left(\mathrm{CH}_{3}\right)_{4} \mathrm{NCl}$ in DMSO leading to the composition $\left[\left(\mathrm{CH}_{3}\right)_{4} \cdot 6 \mathrm{DMSO}\right] \mathrm{C}_{24} \cdot{ }^{29}$ According to the work of Santhanam et al., however, $\mathrm{TBA}^{+}$-cations are intercalated into graphite without a solvation sheath in DMSO and show $d$-values of the intercalated graphite compound of $3.66 \AA^{\circ} .^{30}$ This distance is very similar to the apparently magnesiated graphite in this study and a solvated intercalation might be excluded from this point of view at the present stage as a consequence. Even if solvated intercalation would be neglected at this point and sheer magnesiation/demagnesiation of graphite are the main electrochemical reactions the reason for the low practical capacity still remains to be investigated. Factors such as graphite particle size, electrolyte conductivity, transference number or transport rate at the interfacial layer electrodeelectrolyte and diffusion of magnesium within graphite affect

Table $1 d_{n}$-values of repeated graphite interlayer distances for lithiated and magnesiated graphite intercalation compounds ${ }^{33}$

\begin{tabular}{lcl}
\hline $\begin{array}{l}\text { Degree of intercalation } \\
\mathrm{Li}_{x} \mathrm{C}_{6} / x\end{array}$ & $\begin{array}{l}\text { Graphite interlayer } \\
\text { distance, } d_{\mathrm{n}}(\mathrm{Li}-\mathrm{C}) / \AA\end{array}$ & $\begin{array}{l}\text { Graphite interlayer } \\
\text { distance, } d_{\mathrm{n}}(\mathrm{Mg}-\mathrm{C}) / \AA\end{array}$ \\
\hline 0.00 & 3.358 & 3.356 \\
0.17 & 13.763 & 13.512 \\
0.22 & 10.401 & - \\
0.50 & 7.043 & - \\
1.00 & 3.703 & -
\end{tabular}


the rate capability. In case that only the graphite particle surface is intercalated due to low magnesium diffusivity within the graphene layers and depending on how deep X-rays penetrate the active material, the original graphite peak at $26.70^{\circ} 2 \theta$ should just be diminished in its intensity. Besides, a shifted peak should arise as well indicating the formed intercalation compound or the widening of the graphene layers at least. However, in this study only the diffraction peak as a whole shifts to a lower angle and a second peak appears additionally, thus is, the total magnesiation of the graphite particle occurs provided that X-rays penetrate the entire graphite particles as mentioned above. The high irreversible capacity of the first electrochemical cycle might be truly attributable to electrolyte decomposition and formation of a "SEI-like interphase layer", respectively, because neither an additional diffraction peak of magnesium metal nor the disappearance of the $30.05^{\circ} 2 \theta$ diffraction peak during the charging step can be detected.

\section{Conclusion}

We demonstrate a feasible use of natural graphite based electrodes for their utilization as insertion anodes in rechargeable magnesium-ion batteries. Intercalation of magnesium into graphite is highly reversible and shows distinct demagnesiation (deintercalation) peaks in all electrochemical experiments. By applying more negative vertex potentials magnesium deposition and electrolyte decomposition take place, which lead to passivation of the graphite anode surface and suppress intercalation/deintercalation reactions of magnesium as a consequence. Practical capacities are rather low and exhibit only one tenth of the theoretical capacity ( $\left.372 \mathrm{~mA} \mathrm{~h} \mathrm{~g}^{-1}\right)$ with reference to a hypothetically assumed phase with $\mathrm{Mg}_{0.5} \mathrm{C}_{6}$ as final stage. SEM images can support this assumption of a reversible, non-destructive co-intercalation of solvated $\mathrm{Mg}^{2+}$ ions since no exfoliation of graphite is detected. XRD investigations reveal the widening up of graphite interlayer distances ( $d$-values) but exclude a solvated intercalation of magnesium and solvent at the same time. Even it is rather uncertain we believe that "SEI-like interphase layer" is formed by electrolyte reduction which does not block $\mathrm{Mg}^{2+}$-ion migration. This hypothesis might be supported by the high irreversible capacity obtained in the first cycles.

Taken as a whole, it must be clearly pointed out that the obtained results presented in this study are preliminary and have to be verified for other organic electrolytes consisting of distinct solvents and magnesium salts. Most importantly, there is still uncertainty about the exact reaction mechanisms and whether sheer magnesiation/demagnesiation or cointercalation of graphite take place. Furthermore, it will be necessary to prove the existence and exact stage of magnesiated graphite intercalation compounds. With this study we want to offer our results, explanations and assumptions, respectively, to other research groups encouraging them to determine dependences of intercalation and deintercalation mechanisms of magnesium into and from graphite and to improve practical capacities. As a consequence, we aim at giving the basis for further development and investigations of insertion anodes in combination with conventional organic electrolytes. This will enable the utilization of common current collectors for already developed cathode materials $\left(\mathrm{MnO}_{2}, \mathrm{~V}_{2} \mathrm{O}_{5}\right.$, etc. $)$ simultaneously leading to a rechargeable $3.0 \mathrm{~V}$ magnesium-ion battery in the end.

\section{References}

1 D. Linden and T. B. Reddy, Handbook of Batteries, McGrawHill, New York, 4th edn, 2011.

2 P. Saha, M. K. Datta, O. I. Velikokhatnyi, A. Manivannan, D. Alman and P. N. Kumta, Prog. Mater. Sci., 2014, 66, 1-86.

3 Panasonic, http://industrial.panasonic.com/cdbs/www-data/ pdf2/ACI4000/ACI4000CE17.pdf, accessed December 2015.

4 MIT Technology Review, M. LaMonica, http:// www.technologyreview.com/news/507561/toyota-plugs-awayat-the-next-gen-electric-car-battery/, accessed November 2012.

5 K. Xu, Chem. Rev., 2004, 104, 4303-4417.

6 D. Aurbach, Y. Gofer, Z. Lu, A. Schechter, O. Chusid, H. Gizbar, Y. Cohen, V. Ashkenazi, M. Moshkovich, R. Turgeman and E. Levi, J. Power Sources, 2001, 97-98, 2832.

7 Z. Lu, A. Schechter, M. Moshkovich and D. Aurbach, J. Electroanal. Chem., 1999, 203-217.

8 J. Muldoon, C. B. Bucur, A. G. Oliver, T. Sugimoto, M. Matsui, H. S. Kim, G. D. Allred, J. Zajicek and Y. Kotani, Energy Environ.Sci., 2012, 5, 5941-5950.

9 D. Aurbach, Z. Lu, A. Schechter, Y. Gofer, H. Gizbar, R. Turgeman, Y. Cohen, M. Moshkovich and E. Levi, Nature, 2000, 407, 724-727.

10 D. Lv, T. Xu, P. Saha, M. K. Datta, M. L. Gordin, A. Manivannan, P. N. Kumta and D. Wang, J. Electrochem. Soc., 2013, 160(2), A351-A355.

11 S. Yagi, A. Tanaka, Y. Ichikawa, T. Ichitsubo and E. Matsubara, J. Electrochem. Soc., 2013, 160(3), C83-C88.

12 N. Singh, T. S. Arthur, C. Ling, M. Matsui and F. Mizuno, Chem.Commun., 2013, 49, 149-151.

13 O. I. Malyi, T. L. Tan and S. Manzhos, J. Power Sources, 2013, 233, 341-345.

14 A. Kitada, Y. Kang, Y. Uchimoto and K. Murase, ECS Trans., 2014, 36, 75-80.

15 S. Y. Ha, Y. W. Lee, S. W. Woo, B. Koo, J. S. Kim, J. Cho, K. T. Lee and N. S. Choi, ACS Appl. Mater. Interfaces, 2014, 6, 4063-4073.

16 E. N. Keyzer, H. F. J. Glass, Z. Liu, P. M. Bayley, S. E. Dutton, C. P. Grey and D. S. Wright, J. Am. Chem. Soc., 2016, 138, 8682-8685.

17 M. Zoidl, C. God, P. Handel, R. Fischer, C. Lenardt, M. Schmuck and T. M. Wrodnigg, J. Electrochem. Soc., 2016, 163(10), A2461-A2463.

18 M. Kawaguchi and A. Kurasaki, Chem. Commun., 2012, 48, 6897-6899.

19 Y. Maeda and P. Touzain, Electrochim. Acta, 1988, 1493-1497. 20 D. Pontiroli, M. Aramini, M. Gaboardi, M. Mazzani, A. Gorreri, M. Riccò, I. Margiolaki and D. Sheptyakov, Carbon, 2013, 51, 143-147. 
21 J. Giraudet, D. Claves, K. Guerin, M. Dubois, A. Houdayer, F. Masin and A. Hamwi, J. Power Sources, 2007, 173, 592-598. 22 C. Cazorla, S. A. Shevlin and Z. Y. Guo, Phys. Rev. B: Condens. Matter Mater. Phys., 2010, 82, 155454.

23 M. Katayama, M. Shinoda, K. Ozutsumi, S. Funahashi and Y. Inada, Anal. Sci., 2012, 28, 103-106.

24 D. W. James, R. E. Mayes, W. H. Leong, I. M. Jamie and G. Zhen, Faraday Discuss. Chem. Soc., 1988, 85, 269-281.

25 P. Kurzweil, Advances in Battery Technology for Electric Vehicles, ed. B. Scrosati, J. Garche and W. Tillmetz, Elsevier, 2015, ch. 7, p. 161.

26 S. Komaba, T. Itabashi, B. Kaplan, H. Groult and N. Kumagai, Electrochem. Commun., 2003, 5, 962-966.

27 J. O. Besenhard and H. P. Fritz, J. Electroanal. Chem., 1974, 53, 329-333.

28 J. O. Besenhard, Carbon, 1976, 14, 111-115.

29 J. O. Besenhard, H. Möhwald and J. J. Nickl, Carbon, 1980, 18, 399-405.
30 R. Santhanam and M. Noel, J. Power Sources, 1997, 66, 47-54. 31 J. A. Seel and J. R. Dahn, J. Power Sources, 2000, 147(3), 892898.

32 M. R. Wagner, J. H. Albering, K.-C. Moeller, J. O. Besenhard and M. Winter, Electrochem. Commun., 2005, 7, 947-952.

33 T. Ohzuku, Y. Iwakoshi and K. Sawai, J. Electrochem. Soc., 1993, 140, 2490-2498.

34 H. Kim, J. Hong, G. Yoon, H. Kim, K.-Y. Park, M.-S. Park, W.-S. Yoon and K. Kang, Energy Environ. Sci., 2015, 8, 2963.

35 T. Placke, G. Schmuelling, R. Kloepsch, P. Meister, O. Fromm, P. Hilbig, H.-W. Meyer and M. Winter, Z. Anorg. Allg. Chem., 2014, 640(10), 1996-2006.

36 M. Asada, T. Fujimori, K. Fujii, R. Kanzaki, Y. Umebayashi and S. Ishiguro, J. Raman Spectrosc., 2007, 38, 417-426.

37 Y. Mizutani, T. Abe, M. Inaba and Z. Ogumi, Synth. Met., 2002, 125, 153-159. 